\title{
Russia On World Research Front Of Industrial Scientific Direction
}

\author{
Blaginin Viktor, Smirnova Anastasiya, Ergunova Olga \\ Laboratory of scientometrics \\ Ural State University of Economics \\ Yekaterinburg, Russia \\ Geschenke777@mai.ru
}

\author{
Khudyakova Tatyana \\ Department of Quality Management \\ Ural State University of Economics \\ Yekaterinburg, Russia \\ Khudyakova_t@mai.ru
}

\begin{abstract}
The article is devoted to the analysis of one of the most popular sections of scientometrics - research fronts, in the direction of industrial science. There are quite a large number of serious studies in the field of industry which are highly cited, which confirms their relevance and necessity for the world science. The systematisation of research objects allowed the identification of the leading countries in various industries based on the statistical data provided by Clarivate Analytics. The special role of Russian scientists in the development of this section of scientific knowledge is proven. Despite Russia's insignificant representation on the research front of the division of industry, the authors expect a serious increase in the number of such articles in the near future, which is confirmed by an analysis of the materials of Russian specialists published over the past year. In this state, the most favourable conditions for the realisation of the above-stated hypothesis are created.
\end{abstract}

Keywords-scientometrics, research fronts, industrial scientific direction, Web of Science, Clarivate Analytics, Russian science

\section{INTRODUCTION}

Such section of scientific knowledge as scientometrics has recently been rapidly developing. At the same time, both the scientometrics in general and its section of bibliometry are in demand. Scientometrics is used by the authorities that are responsible for the formation of the scientific potential of the territories. The main task of bibliometrics is the analysis and forecasting of the reflection of the results of scientific activity, scientific research, and collaborations and so on.

Most often in scientific papers, there is an identification of sciencemetry and bibliometry, or the authors simply do not consider it necessary to separate these categories [1]. It is worth noting that the authors of this article will also use them as synonyms, implying a more particular term of bibliometry, because research fronts are analysed on the basis of articles.

The research fronts are also not a new category, especially for scientometric studies conducted by scientists and statisticians of Western Europe and America (in this case the authors can not fail to mention the well-known «Scientometrics» journal, in which the term appeared for the first time) [2,3]. In general, if the bibliometry is a purely statistical science, but gradually embodies the qualitative nature of the data, the category "research front", which is for the most part a category of the bibliometric system, takes a serious step toward meeting a qualitative interpretation of scientific information in databases. The research fronts are clusters of one-volume, highly cited studies (articles) that are in demand at that particular time period. Of course authors and researches understand that the standardised quotability of, for example, works in the field of nuclear physics and medieval history is seriously different. Therefore, the calculation of research fronts takes place deliberately, and the first compilers are specialists of Clarivate Analytics, the owner of the largest database of scientific information - the Web of Science. They are also the developers of the most advanced sciencemeasuring tools, allowing one to evaluate the development of science and its separate areas in a variety of ways. One such method is the evaluation of research fronts in a certain field of scientific knowledge, as well as the geographical analysis of research representatives of this direction. In this article, the authors set themselves the task of assessing research fronts in the industrial scientific field, whose representation is the maximum, since scientific research in this field is of pervasive and maximally applied nature, influencing the economic development of territories and the world economy as a whole [4]. It is also planned to evaluate the works of the Russian Federation and forecast their entry into the world research fronts. 


\section{RESEARCH METHODS AND MATERIALS}

\section{A. Methods}

In study, authors used standard statistical analysis methods, such as

- $\quad$ sampling

- dynamic and variation series

- $\quad$ summary and grouping of statistical observation materials

- methods for searching scientific information

\section{B. Materials}

The analysis is based on the report of the scientific organisations, Institutes of Science and Development and Clarivate Analytics, which is called "Research Fronts 2016" [5]. Statistical data were obtained using a tool "InCites" located on the Web of Science platform.

\section{RESULTS AND DISCUSSION}

The trajectories of industrial scientific research are quite diverse. First of all, industry consists of a large number of directions. And also a lot of scientific research is somehow reflected in the practice of economic activity of industrial enterprises of different countries. With this in mind, it seems necessary to analyse the aforementioned report in detail.

The research fronts in the report "Research fronts 2016" included the following sections:

- Agricultural, plant and animal sciences

- Ecology and environmental sciences

- Geosciences

- Clinical medicine

- Biological sciences

- Chemistry and materials sciences

- Physics

- Astronomy and astrophysics

- Mathematics, computer science and engineering

- Economics, psychology and other social sciences

The methodology for identifying research fronts was based on the allocation of 10 current areas of research (the most frequently cited) in 10 major areas. In this way, 100 research fronts were formed and 80 so-called "emerging ones" were added to these. Emerging ones are those that are recognised as rapidly evolving; they will most likely pass into the category of "hot research fronts" as early as next year.

First of all, it is necessary to formulate a methodology for identifying research fronts in industrial research. As authors have already mentioned, some areas directly or indirectly relate to research in the field of industry (fig.1).

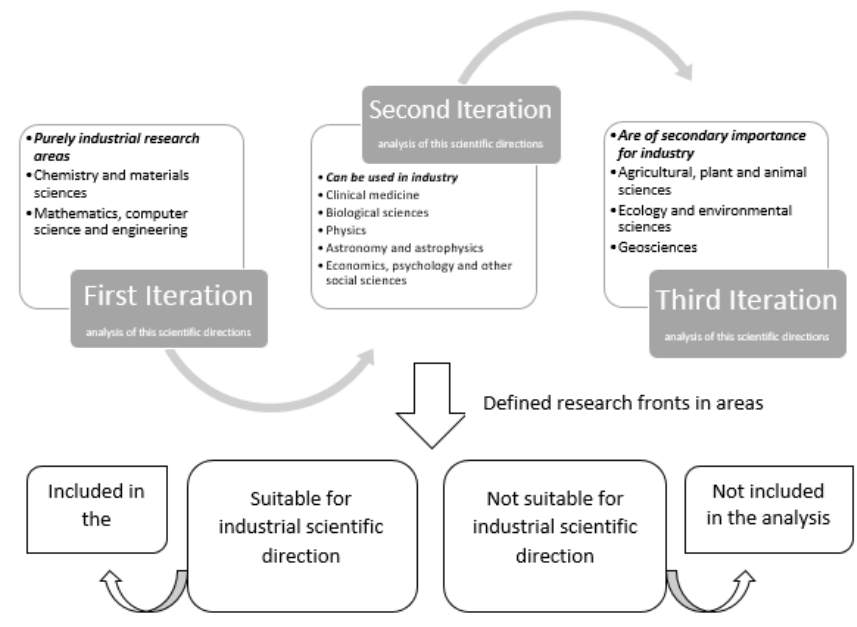

Fig. 1. The methodology of analysis of the research fronts of the industrial scientific direction

Despite the stage-by-stage approach of the proposed methodology, the research began in the opposite direction. First of all, the areas indirectly associated with the direction of scientific research (the third iteration) were examined. They are "Agricultural, plant and animal sciences", "Ecology and environmental sciences", "Geosciences". An example of the research fronts in the report is shown in Figure 2.

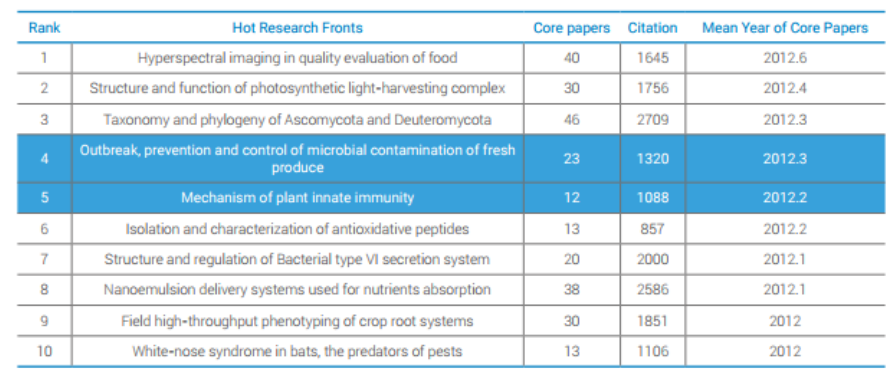

Fig. 2. Top 10 research fronts in agricultural, plant and animal sciences in 2016

In addition to the hot topics, the report for each area contains a retrospective analysis of the formation and development of current research fronts, countries and universities who represent a given subject, i.e. organisations that have made the most serious contribution to the topic, as well as the most interested parties, i.e. the organisations making the most citations for each research front [6]. 
TABLE I. RESEARCH FRONTS OF THE THIRD ITERATION

\begin{tabular}{|l|l|}
\hline Top research front & Area \\
\hline $\begin{array}{l}\text { Structure and function of photosynthetic light- } \\
\text { harvesting complex }\end{array}$ & $\begin{array}{l}\text { Agricultural, plant and } \\
\text { animal sciences }\end{array}$ \\
\cline { 1 - 2 } $\begin{array}{l}\text { Hyperspectral imaging in quality evaluation of } \\
\text { food }\end{array}$ & \\
\cline { 1 - 2 } $\begin{array}{l}\text { Nanoemulsion delivery systems used for } \\
\text { nutrients absorption }\end{array}$ & $\begin{array}{l}\text { Ecology } \\
\text { environmental } \\
\text { sciences }\end{array}$ \\
\hline Ecosystem services & Geosciences \\
\hline Heavy metal contamination of soil and sediment \\
\hline $\begin{array}{l}\text { Next Generation Attenuation (NGA) ground } \\
\text { motion prediction model }\end{array}$
\end{tabular}

The research fronts, most relevant for industrial research, are presented in table 1 . It is clear that themes are mainly aimed at optimising processes and improving the quality of products, which, at the current moment in the development of the world economy, means finding ways to systematise tasks. Particular attention should be paid to the topic of "Ecosystem services", because of the openness of data on environmental pollution and the unfavourable assessments of experts in this field. It is widely believed that it is in industry that green technologies must be introduced as soon as possible. It is also necessary to say that the leaders, as in all other areas of scientific activity, are scientists from the United States.

The middle iteration of scientific areas relevant to industry was analysed more thoroughly. The authors draw attention to the fact that in every major area, the rationale was given for the area most in demand. The topics for the second stage of the study are presented in the table.

TABLE II. RESEARCH FRONTS OF THE SECOND ITERATION

\begin{tabular}{|c|c|}
\hline Top research front & Area \\
\hline $\begin{array}{llll}\text { Clinical } & \text { trials } & \text { of } & \text { direct-acting } \\
\text { antivirals } & \text { (DAAs) } & \text { for } & \text { hepatitis } \\
\text { infections } & & & \end{array}$ & Clinical medicine \\
\hline $\begin{array}{l}\text { Broadly neutralizing antibodies for } \\
\text { HIV vaccine design }\end{array}$ & Biological sciences \\
\hline $\begin{array}{l}\text { Property of metasurfaces and design } \\
\text { of metasurface devices }\end{array}$ & Physics \\
\hline $\begin{array}{l}\text { Solar atmosphere and magnetic field } \\
\text { research based on solar observation } \\
\text { satellites (Solar-B, SDO, IRIS, } \\
\text { STEREO, etc.) }\end{array}$ & \multirow[t]{2}{*}{ Astronomy and astrophysics } \\
\hline $\begin{array}{l}\text { Research on dark matter and the } \\
\text { formation and evolution of galaxy }\end{array}$ & \\
\hline $\begin{array}{l}\text { Global rise of waterpipe/hookah } \\
\text { smoking and its impact on health }\end{array}$ & \multirow[t]{4}{*}{$\begin{array}{l}\text { Economics, psychology and } \\
\text { other social sciences }\end{array}$} \\
\hline $\begin{array}{l}\text { Electronic cigarettes: user } \\
\text { preferences, toxicants, regulatory and } \\
\text { smoking cessation }\end{array}$ & \\
\hline $\begin{array}{l}\text { Global land and natural resource } \\
\text { grabbing }\end{array}$ & \\
\hline $\begin{array}{l}\text { DEA (Data Envelopment Analysis) } \\
\text { based assessment of environmental } \\
\text { and energy efficiency }\end{array}$ & \\
\hline
\end{tabular}

The hepatitis $\mathrm{C}$ virus is a global problem for the world's health systems. According to the World Health Organisation's (WHO) latest statistics, the number of cases of infection in
2015 was 150 million. The chronic form of viral hepatitis $\mathrm{C}$ causes complications in the form of other diseases such as cirrhosis and liver cancer. Each year, about 500,000 people die from these complications. Currently, the topic of clinical trials of direct antiviral drugs for the treatment of hepatitis $\mathrm{C}$ is becoming one of the key research fronts in the field of clinical medicine. The development of therapeutic innovations in the field of the treatment of the hepatitis $\mathrm{C}$ virus involves the production of a new generation of drugs, inextricably linked to the design and subsequent use of high-tech equipment.

The United States has shown the greatest interest among the world scientific community in this research front. American authors published 35 scientific papers, amounting to $92.1 \%$ of the total number, and 645 citations were made by American scientists of work in this research front (48.4\%).

Figures 3 and 4 show the ratings of the top 10 countries and institutions that producing core and citations to work in the research front «Clinical trials of direct-acting antivirals (DAAs) for hepatitis C infections».

\begin{tabular}{|c|c|c|c|c|c|c|c|c|}
\hline $\begin{array}{l}\text { Country } \\
\text { Ranking }\end{array}$ & Country & $\begin{array}{l}\text { Core } \\
\text { Paper }\end{array}$ & Proportion & $\begin{array}{c}\text { Institution } \\
\text { Ranking }\end{array}$ & Institution & $\begin{array}{c}\text { Affiliated } \\
\text { Country }\end{array}$ & $\begin{array}{l}\text { Core } \\
\text { Paper }\end{array}$ & Proportion \\
\hline 1 & USA & 35 & $92.1 \%$ & 1 & Gilead Sciences & USA & 17 & $44.7 \%$ \\
\hline 2 & France & 13 & $34.2 \%$ & 1 & $\begin{array}{l}\text { University of Texas Health Science } \\
\text { Center San Antonio }\end{array}$ & USA & 17 & $44.7 \%$ \\
\hline 3 & Germany & 11 & $28.9 \%$ & 3 & Cornell University & USA & 11 & $28.9 \%$ \\
\hline 3 & Spain & 11 & $28.9 \%$ & 4 & Goethe University Frankfurt & Germany & 10 & $26.3 \%$ \\
\hline 5 & Belgium & 10 & $26.3 \%$ & 4 & Virginia Mason Medical Center & USA & 10 & $26.3 \%$ \\
\hline 5 & UK & 10 & $26.3 \%$ & 6 & AbbVie $C_{0}$. & USA & 8 & $21.1 \%$ \\
\hline 7 & Canada & 9 & $23.7 \%$ & 6 & Johns Hopkins University & USA & 8 & $21.1 \%$ \\
\hline 7 & Italy & 9 & $23.7 \%$ & 8 & University of Florida & USA & 7 & $18.4 \%$ \\
\hline 9 & Australia & 8 & $21.1 \%$ & 8 & University of Pennsylvania & USA & 7 & $18.4 \%$ \\
\hline 10 & New Zealand & 6 & $158 \%$ & 10 & $\begin{array}{l}\text { University of North Carolina Chapel } \\
\text { Hill }\end{array}$ & USA & 6 & $158 \%$ \\
\hline
\end{tabular}

Fig. 3. Top 10 countries and institutions producing core papers in the research front "Clinical trials of direct-acting antivirals (DAAs) for hepatitis C infections" in 2016

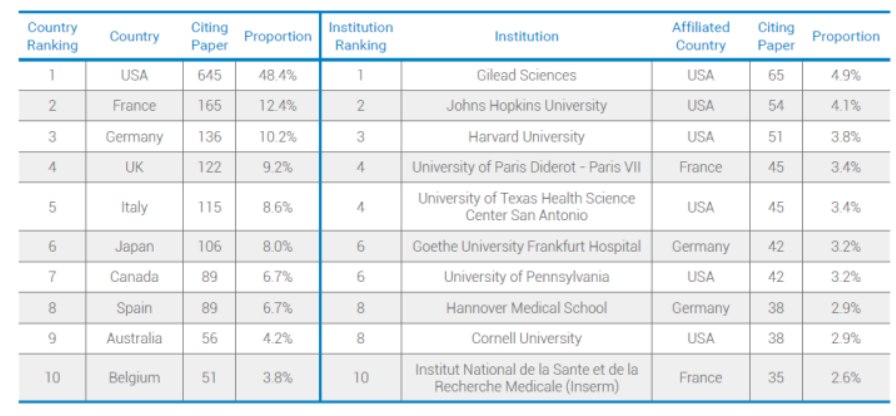

Fig. 4. Top 10 countries and institutions producing citing papers in the research front "Clinical trials of direct-acting antivirals (DAAs) for hepatitis C infections" in 2016

In the field of biological sciences, the most popular research front in industrial research is "Broadly neutralizing antibodies for HIV vaccine design". At the industrial level, the issue of the development and implementing of the HIV vaccine on the market and the mechanism of its action based on accelerating the natural synthesis of neutralising antibodies with a wide spectrum of action by the human immune system has become very actual. The largest number of published studies on this front were made by US authors (18 publications), making up $85.7 \%$ of the total number; France 
and the United Kingdom both took the second place in this structure with 7 each, making up 33.3\%. Among institutions, there are two main leaders working on the topic of neutralising antibodies - the Mount Sinai School of Medicine (7 publications) and the University of Washington (6 publications).

One of the most relevant topics for the field of physical research is the "Property of metasurfaces and design of metasurface devices". The use of metasurfaces presages a breakthrough in the field of industrial optics; this type of surface is already actively used in phototonics in the production of meta-lenses and meta-holograms. The industrial production of films with open metasurfaces presents great prospects for many industries. A thin film of metamaterial can be applied to almost any surfaces and used to cover glass, space suits and satellite housings to reflect ultraviolet and infrared radiation.

In recent years, scientists working in the field of astronomy and astrophysics are more interested in the following topics: «Research on dark matter and the formation and evolution of galaxy» (18 publications, 2939 citations) and «Solar atmosphere and magnetic field research based on solar observation satellites (Solar-B, SDO, IRIS, STEREO, etc.)» (24 publications, 4612 citations).

Research involving obtaining information from solar satellites requires the development of innovative technologies to create new space systems.

The overall direction of research activities, including a combination of economics, psychology and other social sciences, is the consummate link in the second iteration. Among the Top 10 research fronts in this direction, the applicational significance for industry is: «DEA (Data Envelopment Analysis) based assessment of environmental and energy efficiency» (35 publications, 1545 citations), «Global rise of waterpipe/hookah smoking and its impact on health» (23 publications, 1238 citations), «Global land and natural resource grabbing» (27 publications, 1350 citations), «Electronic cigarettes: user preferences, toxicants, regulatory and smoking cessation» (50 publications, 3710 citations).

With the development of the level of industry and the economy, natural resources have been thoughtlessly extracted and exploited for various purposes, as a result of which pollutant emissions are discharged from the products of disintegration and processing in the natural environment, resulting in major problems associated with global warming, climate change and other environmental problems.

Reestablishing the balance between industrial pollution and economic growth has become an important political issue. Governments have strengthened regulations in the name of sustainable development. The assessment of environmental and energy efficiency has become one of the most important issues in world politics, since its essence is not just in understanding environmental performance at a regional macro level, but also in obtaining detailed information to develop and implement systems of environmental management and a policy of energy consumption at the micro level. The DEA has become the most popular approach in assessing environmental performance in recent years.

Figure 5 reflects top regions and institutions producing the 35 core papers in the research front «DEA (Data Envelopment Analysis) based assessment of environmental and energy efficiency»

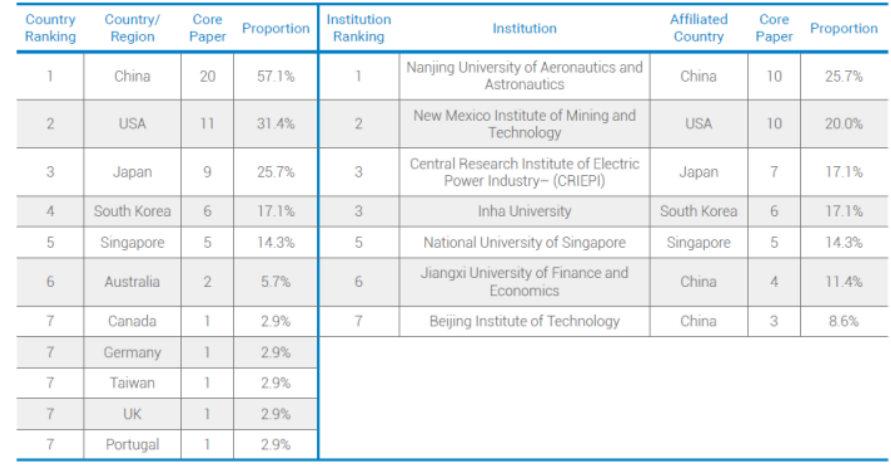

Fig. 5. Top countries/regions and institutions producing 35 core papers in the research front "DEA (Data Envelopment Analysis)-based assessment of environmental and energy efficiency" in 2016

Proceeding from the remark initially accepted about the reverse direction of the analysis, the areas of strictly industrial research have been examined last (first iteration). The latter includes two areas - «Chemistry and materials sciences» and «Mathematics, computer science and engineering».

TABLE III. RESEARCH FRONTS OF THE FIRST ITERATION

\begin{tabular}{|c|c|}
\hline Top research front & Area \\
\hline Non-Fullerene organic solar cells & \multirow{10}{*}{$\begin{array}{l}\text { Chemistry and } \\
\text { materials sciences }\end{array}$} \\
\hline Trifluoromethylthiolation reaction & \\
\hline $\begin{array}{l}\text { Triboelectric nanogenerators as a new energy } \\
\text { technology }\end{array}$ & \\
\hline $\begin{array}{l}\text { Non-noble-metal electro-nanocatalyst for hydrogen } \\
\text { evolution }\end{array}$ & \\
\hline Gold-catalyzed organic synthesis & \\
\hline High-efficiency perovskite solar cells & \\
\hline $\begin{array}{l}\text { Graphene-semiconductor } \quad \text { nanocomposite } \\
\text { photocatalyst }\end{array}$ & \\
\hline Phosphors for white LEDs & \\
\hline Graphene nanofiltration membrane & \\
\hline Sodium-ion batteries & \\
\hline $\begin{array}{l}\begin{array}{l}\text { Hesitant fuzzy sets with their application in } \\
\text { decision making }\end{array} \\
\end{array}$ & \multirow{7}{*}{$\begin{array}{l}\text { Mathematics, } \\
\text { computer science } \\
\text { and engineering }\end{array}$} \\
\hline Configuration design and heat transfer analysis & \\
\hline Keller-Segel chemotaxis model & \\
\hline $\begin{array}{l}\text { Solving several classes of partial differential } \\
\text { equations }\end{array}$ & \\
\hline $\begin{array}{l}\text { The internet of things, cloud manufacturing and } \\
\text { related information technology services }\end{array}$ & \\
\hline Multiple-input multiple-output (MIMO) systems & \\
\hline Research on measurement-device-independent & \\
\hline
\end{tabular}


quantum key distribution

State of charge estimation and aging mechanisms of Li-ion batteries used in electric vehicles

Nanoscale zero-valent iron (ZVI) for treatment of groundwater and wastewater

Bio-inspired algorithms and its optimization

The research fronts in chemistry and materials sciences in 2016 concerned topics, including nanomaterials, batteries, organic chemistry and luminescent materials.

The topic "Phosphors for white LEDs" was listed in the Top 10 research fronts for two consecutive years. Luminescent materials have become an indispensable light source for the new generation of industry and display systems thanks to its unique properties, including energy efficiency, environmental friendliness, small volume and long service life.

The subject of nanomaterials covers three related scientific areas: graphene, nanocatalysts and triboelectric nanogenerators. A particularly promising direction for graphene is its potential use in photocatalysis and membrane filtration.

With regard to batteries, vessels for fullerene batteries have become representative of a new direction in organic studies of solar cells - "Non-fullerene organic solar cells" (41 publications, 2249 citations). Sodium-ion batteries replaced lithium-ion batteries, which are represented in last year's ranking.

Fronts related to electro-nanocatalysts and photonanocatalysts appear in the Top 10 ranking because of the high productivity of nanocatalysts. Perovskite solar cells have become the subject of a new front of research in the past year and the most popular front this year (fig.6). Noble metals acting as catalysts in organic synthesis reactions have always been fairly popular topics in organic chemistry. Last year, the topic of copper catalysts was ranked highest, while in 2016, this position was occupied by gold catalysts.

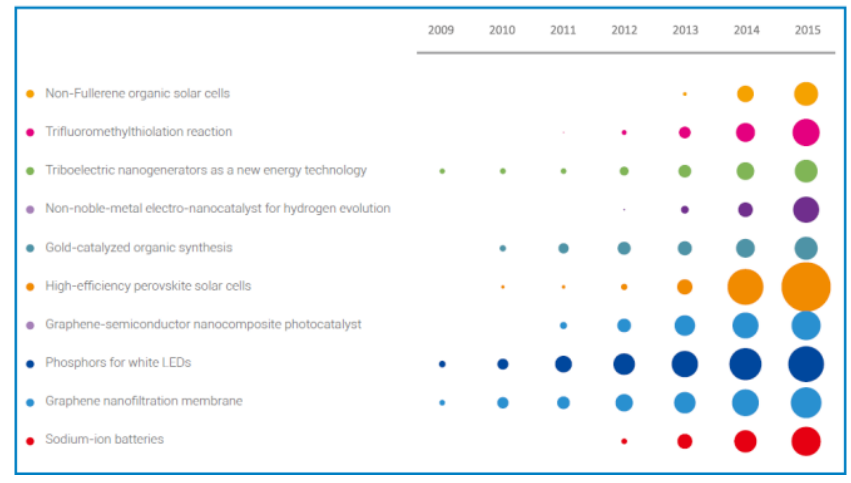

Fig. 6. Citing papers of the Top 10 research fronts in chemistry and materials science in 2016

Figure 7 presents a rating of the TOP-10 research fronts in the area of chemistry and material sciences.

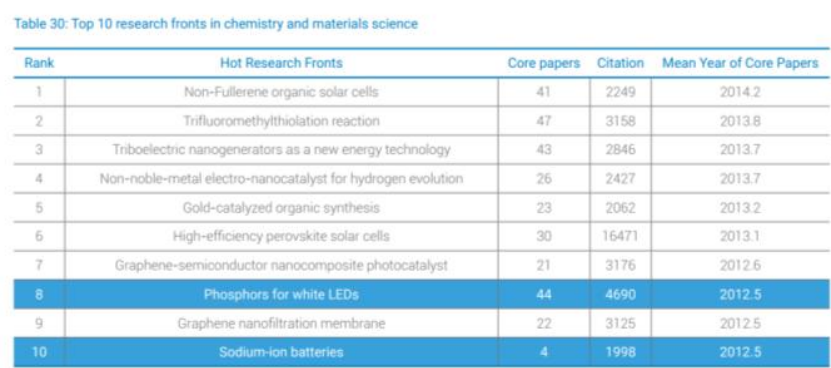

Fig. 7. Top 10 research fronts in chemistry and materials science in 2016

From the data presented in Figure 7, it can be concluded that the largest number of publications was made in the area «Trifluoromethylthiolation reaction» in the amount of 47 papers, while the largest number of citations (16471) was obtained by the direction «High-efficiency perovskite solar cells»

Top 10 research fronts in mathematics, computer science and engineering are mainly focused on such directions as

- «Hesitant fuzzy sets with their application in decision making»;

- «Configuration design and heat transfer analysis»;

- «Keller-Segel chemotaxis model»;

- «Solving several classes of partial differential equations»;

- «The internet of things, cloud manufacturing and related information technology services»;

- «Multiple-input multiple-output

(MIMO) systems»;

- «Research on measurement-device-independent quantum key distribution»;

- «State of charge estimation and aging mechanisms of Li-ion batteries used in electric vehicles»;

- «Nanoscale zero-valent iron (ZVI) for treatment of groundwater and wastewater»;

- «Bio-inspired algorithms and its optimization».

Among the directions that are gaining increasing interest in the global scientific community, and are gradually being introduced into the list of the first iteration, the so-called "emerging research fronts", authors are obliged to mention such direction as «Energy management strategies of hybrid electric bus» (7 publications, 143 citations) (fig.8).

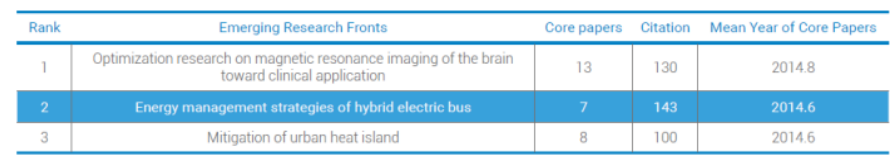

Fig. 8. Emerging research fronts in mathematics, computer science and engineering in 2016 
The energy crisis and environmental pollution in general have become the main challenge for the automotive industry and urban management. Conducting research in the field of energy conservation and the development of transport aggregates that do not cause serious damage to the biosphere is very important for the sustainable development of countries and cities. The hybrid electric bus is one of the types of hybrid vehicle that combines a conventional internal combustion engine with an electric motor system.

By optimising the ways in which various energy sources complement each other, vehicle dynamics, safety and comfort can assures by increasing energy-saving performance. At the same time, the hybrid electric bus is an affordable and suitable vehicle for industrialisation processes and is considered the most promising alternative to conventional buses. Therefore, the study of foundational technologies for the the production of hybrid electric buses is of great practical importance.

\section{CONCLUSION}

The analysis of research areas associated with industrial technologies is very important at the current stage of the evolution of world science. Industry forms the largest gross product in every country directly or indirectly; Russia, since it is home to a rich industrial infrastructure, must create breakthrough technologies in this area in order to take leading positions in emerging areas of research [7].

The Russian Academy of Sciences is fifth among all world organisations directly or indirectly related to scientific research activity in a number of publications in the Web of Science Core Collection platform, behind Harvard University and before the Chinese Academy of Sciences (fig. 9).

\begin{tabular}{|c|c|c|c|c|c|}
\hline Name & Rank & $\begin{array}{l}\text { Web of Sclence } \\
\text { Docunnents }\end{array}$ & $\begin{array}{l}\text { Category Nomulazer clation } \\
\text { Impact }\end{array}$ & $\begin{array}{l}\text { nness } \\
\text { Clleod }\end{array}$ & $\begin{array}{c}\text { \%Docs } \\
\text { Cresd }\end{array}$ \\
\hline 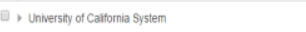 & 1 & $1,24,065$ & 1.83 & 36.995 .526 & $7256 \%$ \\
\hline 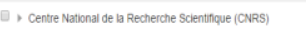 & 2 & 712,130 & 1.21 & $15,289,208$ & $81.61 \%$ \\
\hline Q. Uninersty o t Lonoon & 3 & 625,405 & 1.52 & $13.073,349$ & $6625 \%$ \\
\hline 9, Hanard Univessity & 4 & 598,546 & 214 & $22.24,535$ & $71.35 \%$ \\
\hline D. Russian Acaterny of Sclences & 5 & 507,486 & 0.51 & $4.067,098$ & $67.6 \%$ \\
\hline 1. Chinese Academy of Scences & 6 & 49,998 & 1.02 & $5,859,220$ & 75.635 \\
\hline ๑, Unted Sales Departrment of Enetgy (DOE) & 7 & 414,366 & 1.65 & 11.253 .053 & 77.015 \\
\hline 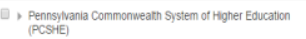 & 8 & 401,107 & 151 & 9.042 .40 & $67.68 \%$ \\
\hline ๑, Firica State Unversyty System & 9 & 361,999 & 1.3 & 6.236 .595 & $68.1 \%$ \\
\hline U, Nationa Instrutues of Heath (NH) - USA & 10 & 388,497 & 192 & 14.512.306 & $74.82 \%$ \\
\hline
\end{tabular}

Fig. 9. Top organizations by the number of publications in the world in Web of Science Core Collection

An analysis of this rating suggests that other Russian organisations, which include universities in the 5-TOP-100 programme, have quite low indicators for this criterion. From this, researhes can conclude that Russian authors are represented at a relatively low rate in international publications.

The President of the Russian Federation, Vladimir Putin, in his decree "On measures to implement government policy in education and science" on 7 May, 2012, formulated a global goal - the entry of Russian research into the international scientific space [8]. To achieve this, the most important task was the inclusion of scientific periodicals published in Russia in Web of Science and Scopus, the databases of foreign citations.

The creation of the Russian Science Citation Index (RSCI) database on the Web of Science platform is a good example of the implementation of this presidential decree. As a project of Russian origin, RSCI was implemented on the basis of the well-known informational and analytical RSCI system. In 2015, during a multi-stage selection process, 652 Russian advanced journals were selected and included in the RSCI database [9]. The metadata of the publication of these journals for a ten-year period are currently available to foreign authors for informational purposes, which certainly justifies the positive dynamic in the process of integrating Russian science into the international scientific environment by improving collaboration in the scientific sphere.

Indeed, such international cooperation is a necessity for today's scientific community, especially for Russia. Indeed, experts at Clarivate Analytics argue that around 2/3 of all highly-cited publications are produced by international teams of authors. Russian authors do not often form part of these teams, however. The information in figure 9 confirms that, although the share of RAS publications, cited at least once, is $67.6 \%$, the overall number of citations is several times smaller than that of leading organisations. The standardised citation of publications by the Russian Academy of Sciences also proves this thesis; this number is only half of the world average number of citations.

This all confirms the need to improve Russian authors' quality of work and to increase its relevance. Naturally, the demand for publications depends on a number of endogenous and exogenous factors, among which the quality of technical equipment available in the country, investment in scientific activity, and the formation of priority areas in the development of science are the most crucial. The transition from one technological structure to another is a long and expensive process, while the effect of investment is difficult to assess, but it is clear that the level of this type of investment is already quite high in Russia.

Purposeful, long-term work on the quality of research must be carried out. It may take decades to achieve meaningful results in this endeavour. Russia does not have this sort of time; the country's backwardness requires prompt intervention to integrate Russian science into foreign spaces. Although the amount of Russian science in foreign databases is growing each year, country is represented only in one research front, wich is called "Phosphors for white LEDs". 


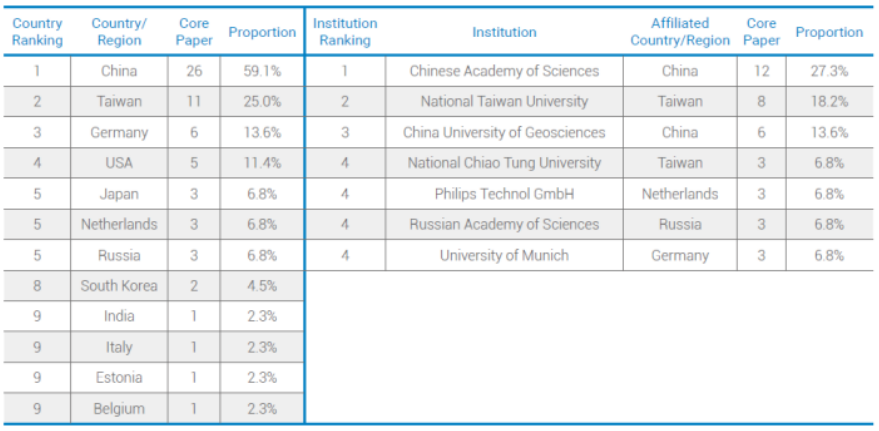

Fig. 10. Top regions and institutions producing core papers in the research front «Phosphors for white LEDs»

The dependence of many regions and monocities on industry is high. That is why these statistics is not encouraging nowardays. The Russian economy needs breakthrough technologies to be developed on its territory. With an understanding of the situations, Russian leaders in science are already realising the need to take into account these areas of research. Financing organizations should give preference to such scientific studies. This could become an area not just of growth, but also of the country's socio-economic development as a whole. Favourable conditions have been created in Russia for the most urgent and groundbreaking research. Even taking into account the country's serious backwardness, authors predict an increase in Russian representation in research in general and in industry in particular.

This will allow Russia to make a leap in the evolution of its knowledge economy and to take the country to a new technological level, forming a positive environment for investment [10]. The implementation of policy intended to encourage entry into important areas could be done on the basis of internal audits of research areas on the statistical data contained in the Russian Index of Scientific Citation. The allocation of local areas of research and their integration into the external environment will give impetus to the development of Russian science and will allow us to confront the exogenous challenges of the modern time.

\section{References}

[1] L. Bornmann, R. Haunschild, Does evaluative scientometrics lose its main focus on scientific quality by the new orientation towards societal impact? Scientometrics, 110(2), pp. 937-943, 2016.

[2] J. Kosten, A classification of the use of research indicators. Scientometrics, 108(1), pp. 457-464, 2016.

[3] K. Fujita, Y. Kajikawa, J. Mori, I. Sakata, Detecting research fronts using different types of weighted citation networks. Journal of engineering and technology management, 32, pp. 129-146, 2014.

[4] JS. Liu, LYY. Lu, WM. Lu, Research fronts in data envelopment analysis. OMEGA-International journal of management science, 58, pp. 33-45, 2016.

[5] Chinese Academy of Sciences, Clarivate Analytics. Research Fronts, 2016.

[6] E. Schiebel, Research fronts and areal density of bibliographically coupled publications. Proceedings of ISSI 2011: The 13th conference of the international society for scientometrics and informetrics, Vol. S1 and 2, pp. 756-762, 2011.

[7] P. E. Kasyanov, Scientometrics in the anti-crisis management of scientific research, 2016, Retrieved from http://hdl.handle.net/10995/43145

[8] Presidential Decree of Russian Federation "On measures to implement government policy in education and science", et seq., 2012.

[9] Russian science citation index. (n.d.). Retrieved from https://elibrary.ru/defaultx.asp

[10] A.I. Matveeva, V.A. Blaginin, Scientometrics indicators as a sphere of individual investment of lectures. Bulletin of Economics, Law and Sociology, 4, pp. 249-254, 2016. 